\title{
Idiopathic macular hemorrhage
}

\author{
Mina Abdelmseih* \\ Department of Ophthalmology, Augenärzte am Meer Clinic, Germany
}

\begin{abstract}
A case of Idiopathic Macular Hemorrhage (IMH) is described in a 26-year-old female patient presented with a sudden unilateral central scotoma in her left eye without any precipitating factors her vision was 20/40 in the left eye (OS) and Fluorescein angiography showed a well-defined hypofluorescent area corresponding to the macular Hemorrhage. An optical coherence tomography (OCT) scan revealed an intraretinal hemorrhage. This case is unusual, in that the IMH developed in a young lady with no significant past medical history and with the absence of retinal, choroidal, systemic or autoimmune diseases, medications, allergies, straining or any family history of eye diseases that leads to an IMH diagnosis by exclusion. Idiopathic Macular Hemorrhage is generally a disorder that primarily affecting patients younger than 40 years and can cause sudden unilateral loss of vision. It usually occurs in an otherwise healthy eye and mostly females. The exact pathogenesis of IMH remains unclear and poorly understood. Conservative management is observation of complete spontaneous resolution, which occurs within few weeks.
\end{abstract}

\section{Case report}

A 26-year-old Caucasian female presented with a central scotoma in her left eye 2 days ago without any precipitating factors. She was referred with macular hemorrhage OS. Blood pressure (BP) was normal, and there was no history of any systemic diseases as hypertension, diabetes, medications, allergies, Straining or any family history of eye diseases.

The best corrected visual acuity (BCVA) for far and near was 20/20 OD and 20/40 OS. Amsler grid was unremarkable on both eyes. Color vision was intact in each eye on Ishihara Pseudo isochromatic plates.

Pupillary responses were equal, round and reactive to light with no afferent defect O.U. Extraocular muscle movements were normal and unrestricted in all positions of gaze O.U. Cover test demonstrated orthophoria at distance.

Gross inspection of the face and lids was negative for ecchymosis, edema or asymmetry. Anterior segment evaluation on biomicroscopy revealed that the eyelids and lashes were clear without evidence of inflammation. The corneas were clear and without evidence of scarring, edema, neovascularization, infiltrates or dendrites. The bulbar and palpebral conjunctivae were clear without injection, chemosis, melanosis, papillae or follicles. The anterior chambers were deep and quiet with absence of cells or flare, hyphema or hypopyon. The irides were flat and without transillumination defects or other signs of atrophy, tears, nodules or neovascularization. No posterior synechiae were present. Anterior chamber angles were estimated to be grade 4 O.U. by the Van Herick method. Intraocular pressure measured 17/18mm Hg O.U. at 3:25 p.m.

A dilated posterior segment evaluation of each eye revealed clear crystalline lenses without opacification or congenital cataract. No red or white cells were found in the vitreous of either eye and there was no evidence of posterior vitreous detachment or syneresis. Dilated ophthalmoscopy with did not reveal any retinal holes, tears, detachments or vitreous traction. The optic nerve measured $0.3 \mathrm{~mm}$ in the horizontal and vertical meridians, and was pink, well-perfused and round with distinct margins in both eyes. I saw no notching, beanpodding, Drance hemorrhage or retinal nerve fiber layer loss in either eye.

The macula of the right eye was unremarkable and demonstrated a positive foveal reflex. However, a macular exam of the left eye revealed a small, isolated macular haemorrhage (Figure 1)

I performed color fundus photography on left eye (Figure 1) On FA, there was preretinal blockage OS, An optical coherence tomography (OCT) scan revealed an intraretinal hemorrhage as well as an area of black located below the hemorrhage (an artifact representing blocked light).

I infomed the patient that she should be observed and reassured her that this condition would likely resolve with short time (Figure1-7).

\section{Prognosis}

Excellent. Complete resolution of the intraretinal hemorrhage was seen in 3 weeks .

\section{Differential diagnoses}

Diabetic retinopathy (DR), a microangiopathy affecting all of the small retinal vessels, such as arterioles, capillaries and venules, is characterized by increased vascular permeability, ocular haemorrhages, lipid exudate, by vascular closure mediated by the development of new vessels on the retina and the posterior vitreous surface [1].

Hypertensive retinopathy signs can be broadly classified into arteriolar changes (generalized arteriolar narrowing, focal arteriolar narrowing, arteriovenous nicking and arteriolar wall opacification) and more advanced retinopathy lesions (microaneurysms, blot and flame-shaped haemorrhages, cotton-wool spots, hard exudates and optic disk swelling). With the exception of disk swelling, these signs

Correspondence to: Mina Abdelmseih, Department of Ophthalmology, Augenärzte am Meer Clinic, 26389 Wilhelmshaven, Germany; E-mail: dr.mina. abdelmseih@gmail.com

Received: June 07, 2017; Accepted: June 24, 2017; Published: June 26, 2017 


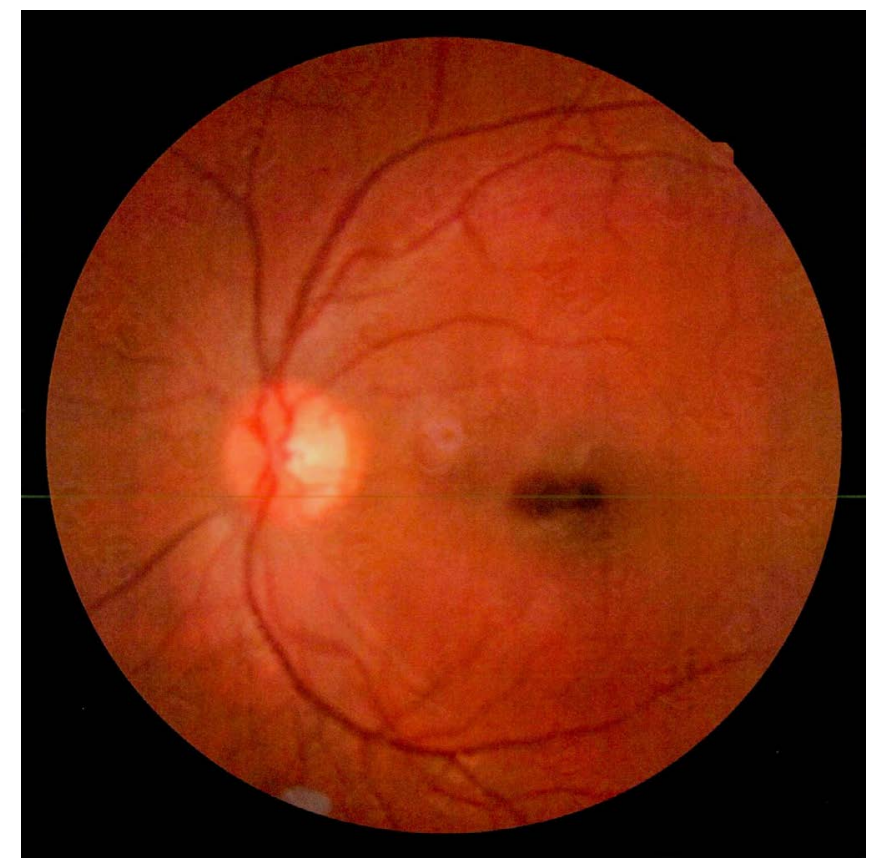

Figure 1. Color Fundus Photography showing Left isolated macular haemorrhage.
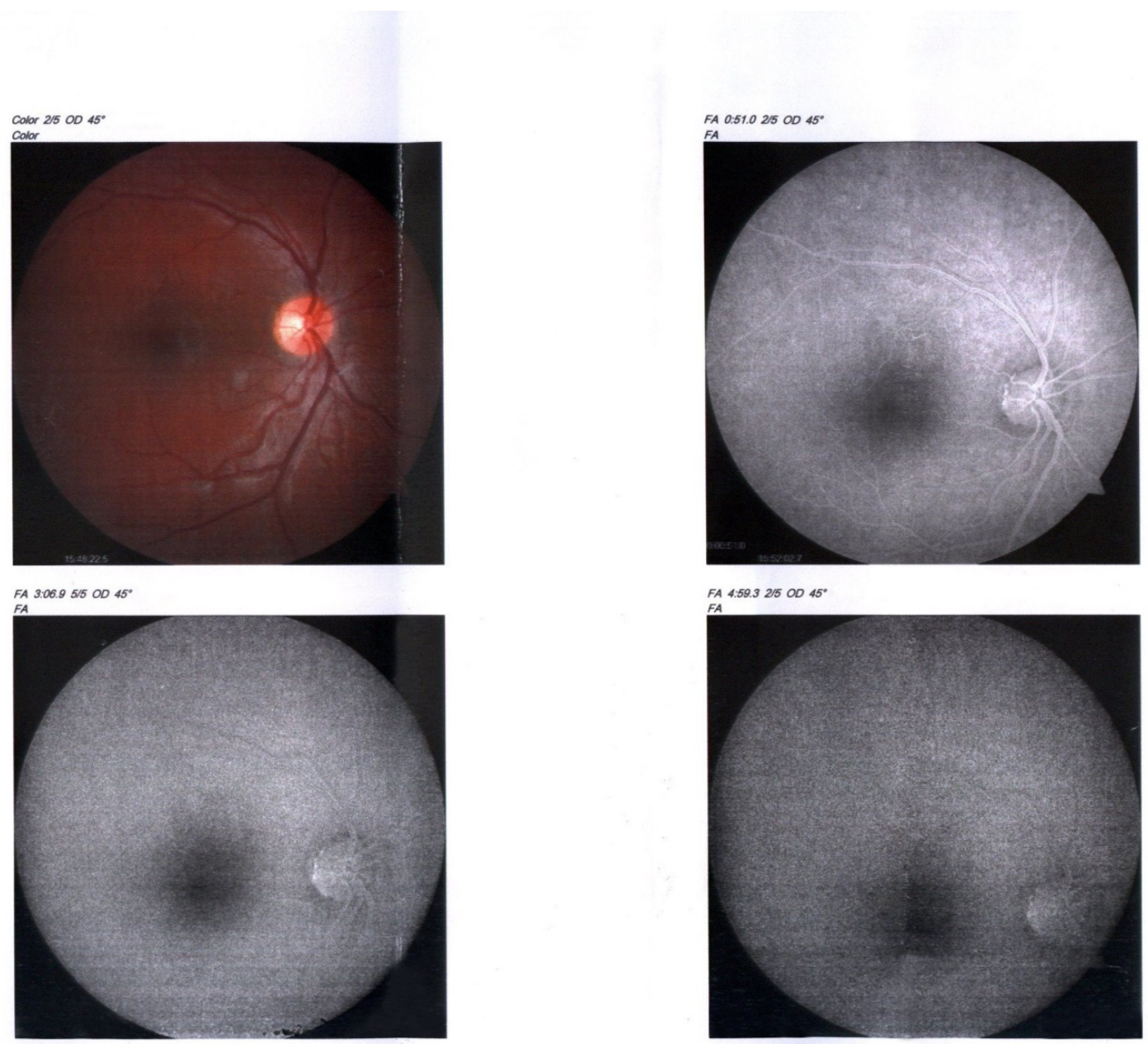

Figure 2. Fundus fluorescein angiography (Right Eye) showing no abnormality. 

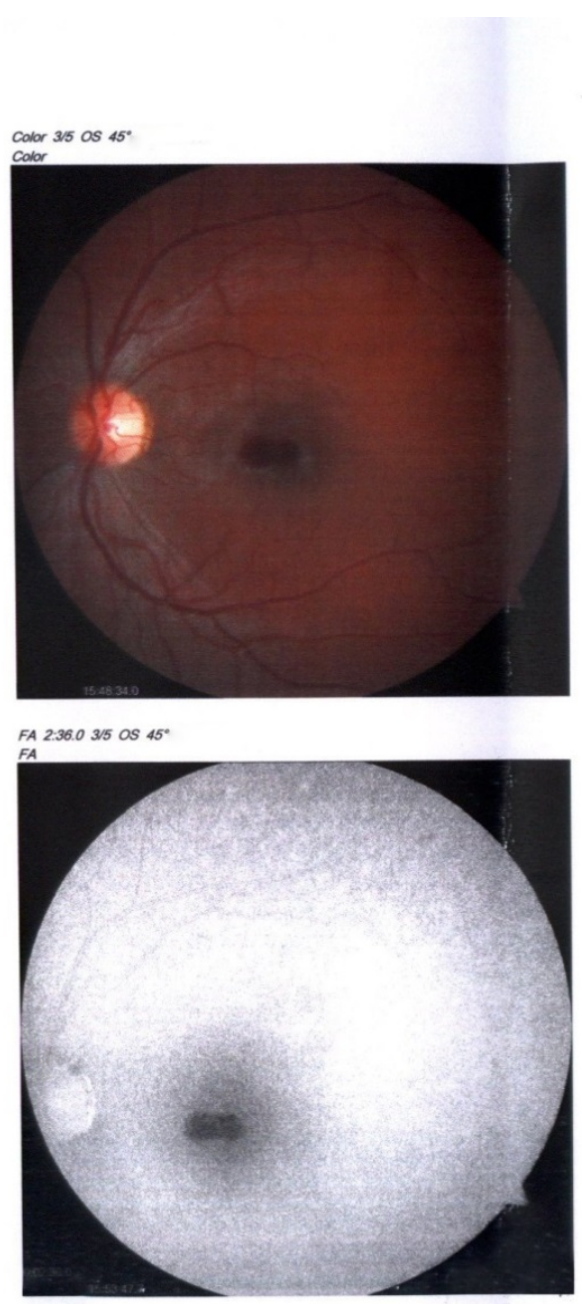
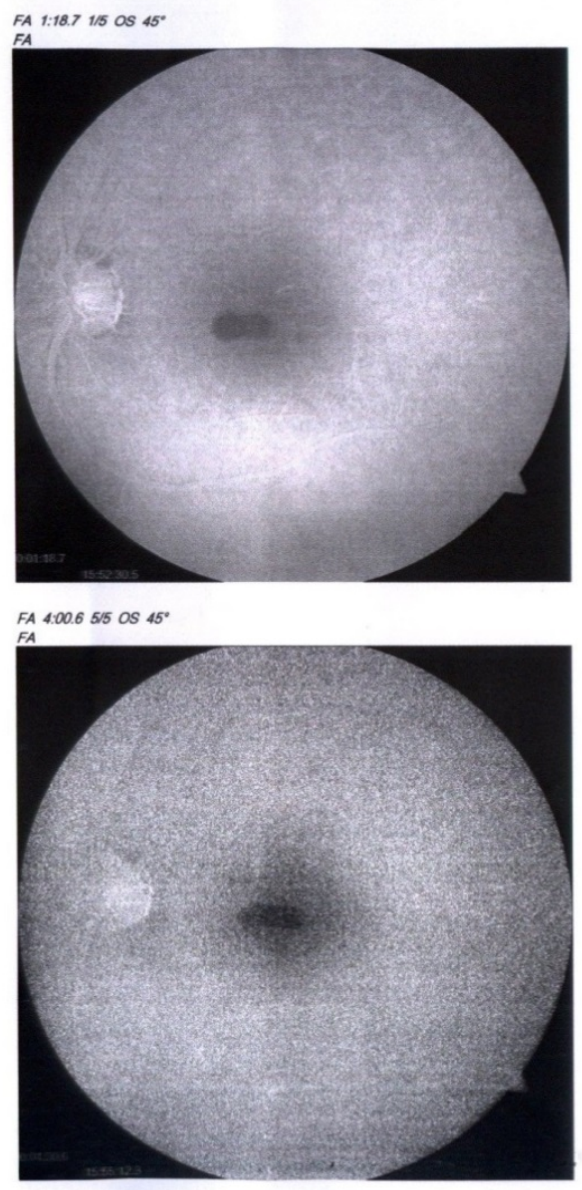

Figure 3. Fundus fluorescein angiography (Left eye) showing preretinal blockage due to hemorrhage.

can be detected fairly frequently in adult populations, even in persons without a known history of hypertension [2].

Valsalva retinopathy was first described by Duane1 in 1972 for preretinal haemorrhages occurring as a result of sudden rise in venous pressure as seen in Valsalva manoeuvre. It is an uncommon condition and has been reported to occur with various forms of Valsalva stress such as weight lifting, physical exercise, balloon blowing, birth labour etc. The present case developed Valsalva retinopathy following a bout of emesis. Valsalva retinopathy is typically seen in young males. Ophthalmologic examination reveals either a circular or a bilobed haemorrhage which sometimes has a fluid level associated with it [3].

Idiopathic Macular Telangiectasia Type 1 :This congenital or developmental form of IJFT occurs predominantly in males and is typically unilateral (97\% of cases).Although the onset of symptoms can occur at any age, the mean age at presentation is 40 years. On biomicroscopy, prominent easily visible telangiectatic retinal capillaries, with variable-sized aneurysmal dilations are a consistent hallmark of this type of IJFT. The telangiectasis usually involves a twodisc diameter area or greater temporal to the fovea .Macular edema and lipid deposition of variable amount is a characteristic feature. Of note, no blunted right-angled venules, superficial vitreoretinal interface crystalline deposits, plaques of pigment epithelial hyperplasia, intraretinal pigment migration or subretinal neovascularization are seen in this type of IJFT [4].

Sickle cell eye disease is characterized by microvascular occlusion that affects the peripheral retinal vasculature and results in retinal ischemia and the development of proliferative sickle cell retinopathy. Complications of proliferative sickle cell retinopathy such as vitreous hemorrhage and retinal detachment are the most common causes of visual loss in this disease [5].

Radiation retinopathy is a chronic and progressive condition that results from exposure to any source of radiation. It might be secondary to radiation treatment of intraocular tumors such as choroidal melanomas, retinoblastomas, and choroidal metastasis,.. The condition manifests as a radiation vasculopathy clinically seen as microaneurysms and telangiectases, with posterior development of retinal hard exudates and hemorrhages, macular edema, neovascularization and tractional retinal detachment [6].

Purtscher's retinopathy presents to the clinician as loss of vision in a patient with a history of a possible precipitating event such as recent major trauma, pancreatitis, childbirth or renal failure. The ophthalmological picture is one of ischaemia at the posterior pole with white patches of oedema and haemorrhages concentrated around the optic disc [7]. 

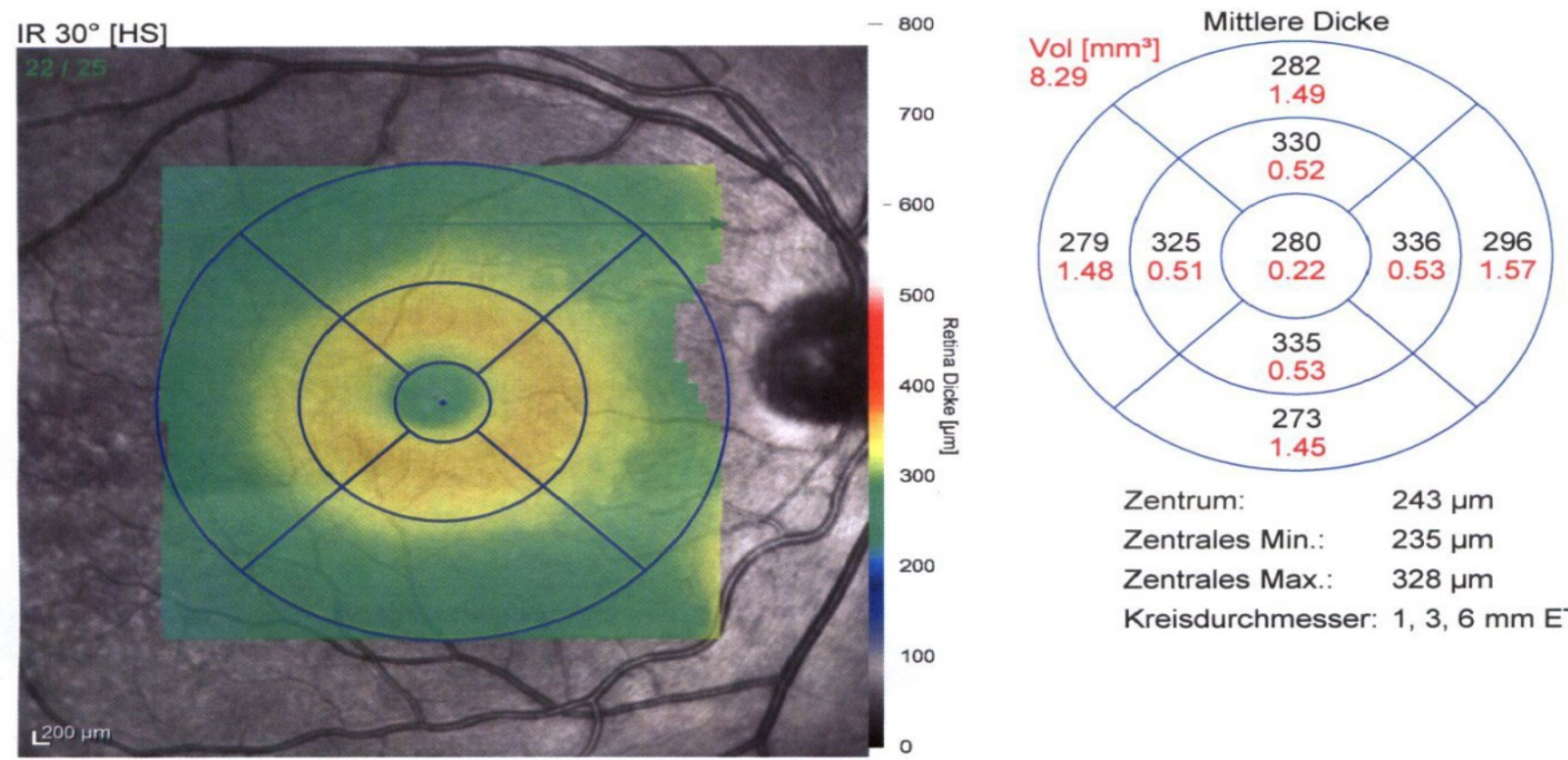

OCT $20^{\circ}(6.0 \mathrm{~mm}) \mathrm{ART}(10) \mathrm{Q}: 24$ [HS]

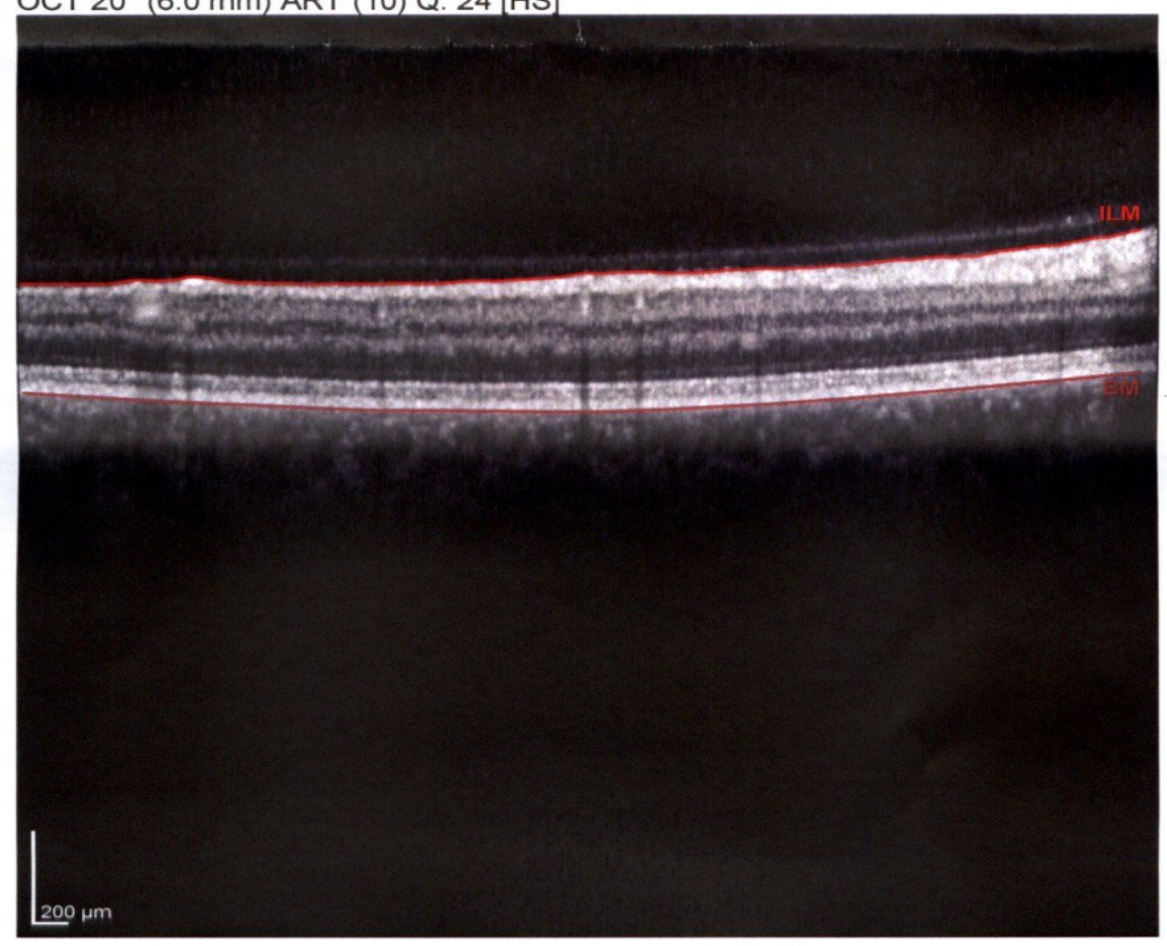

Notizen:

Unterschrift:

Software Version: 6.3.4

www.HeidelbergEngineering.com

Dickenkarten-Einzeluntersuchung

Figure 4. Optical Coherence Tomography (OCT) (Right Eye) showing no abnormality. 

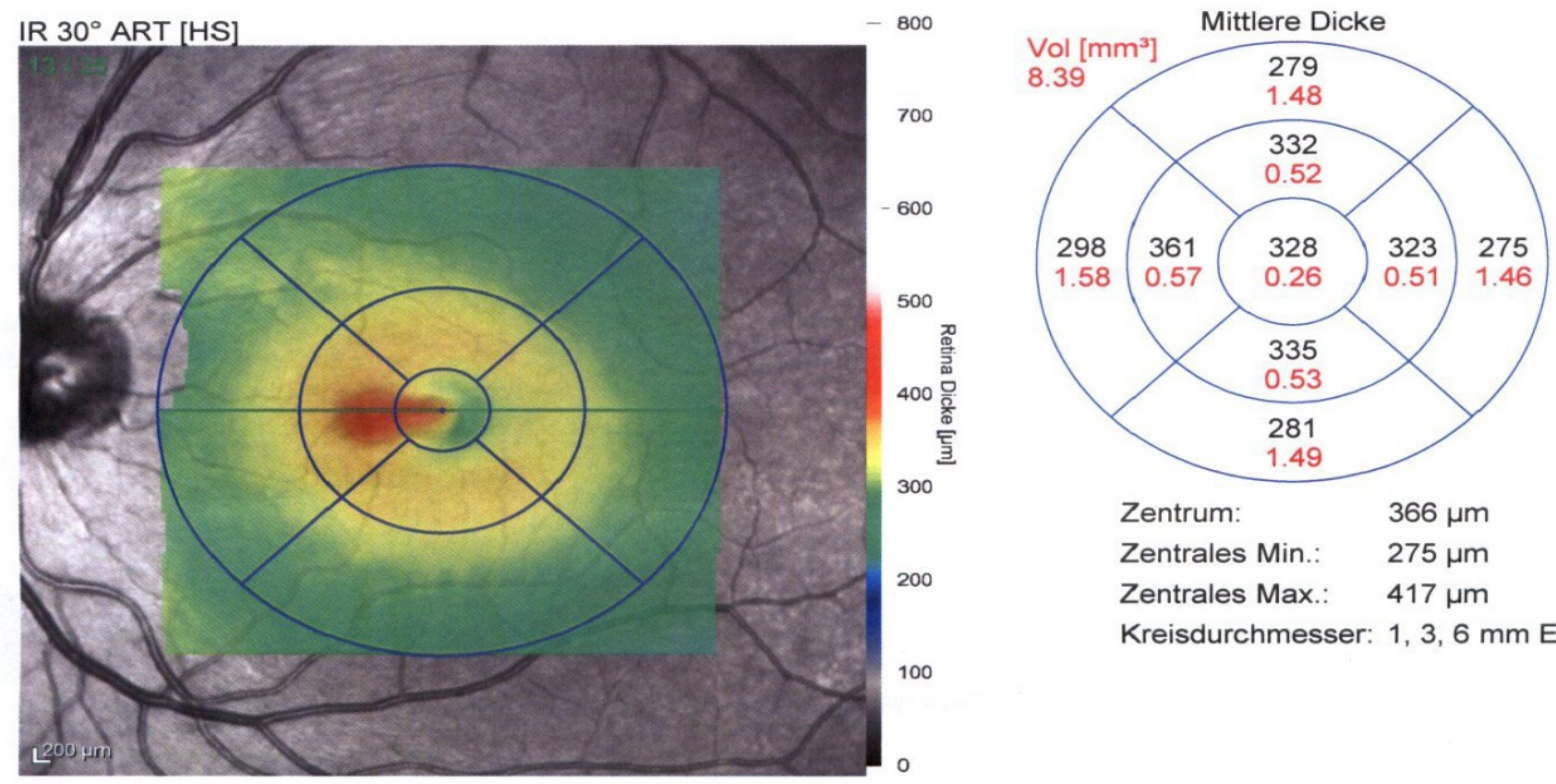

Kreisdurchmesser: 1, 3, 6 mm ETDRS
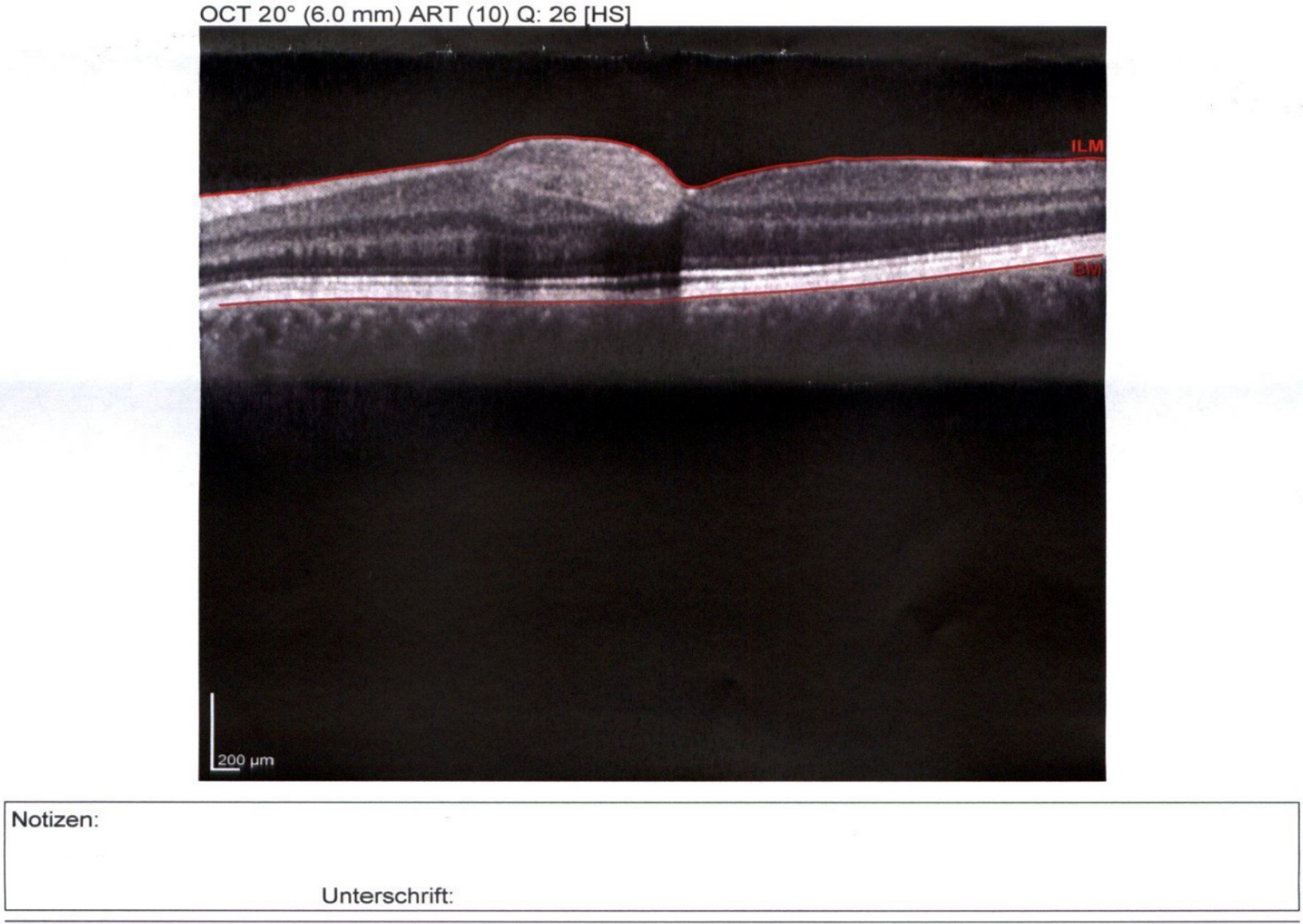

Figure 5. Optical Coherence Tomography (OCT) (Left Eye) showing an intraretinal hemorrhage. 
RNFL-Einzeluntersuchung OU

SPECTRALIS $\otimes$ Tracking Laser Tomographie
口HEIDELBET드 ㅌㄷㅁㅌㄷㄷㅁ
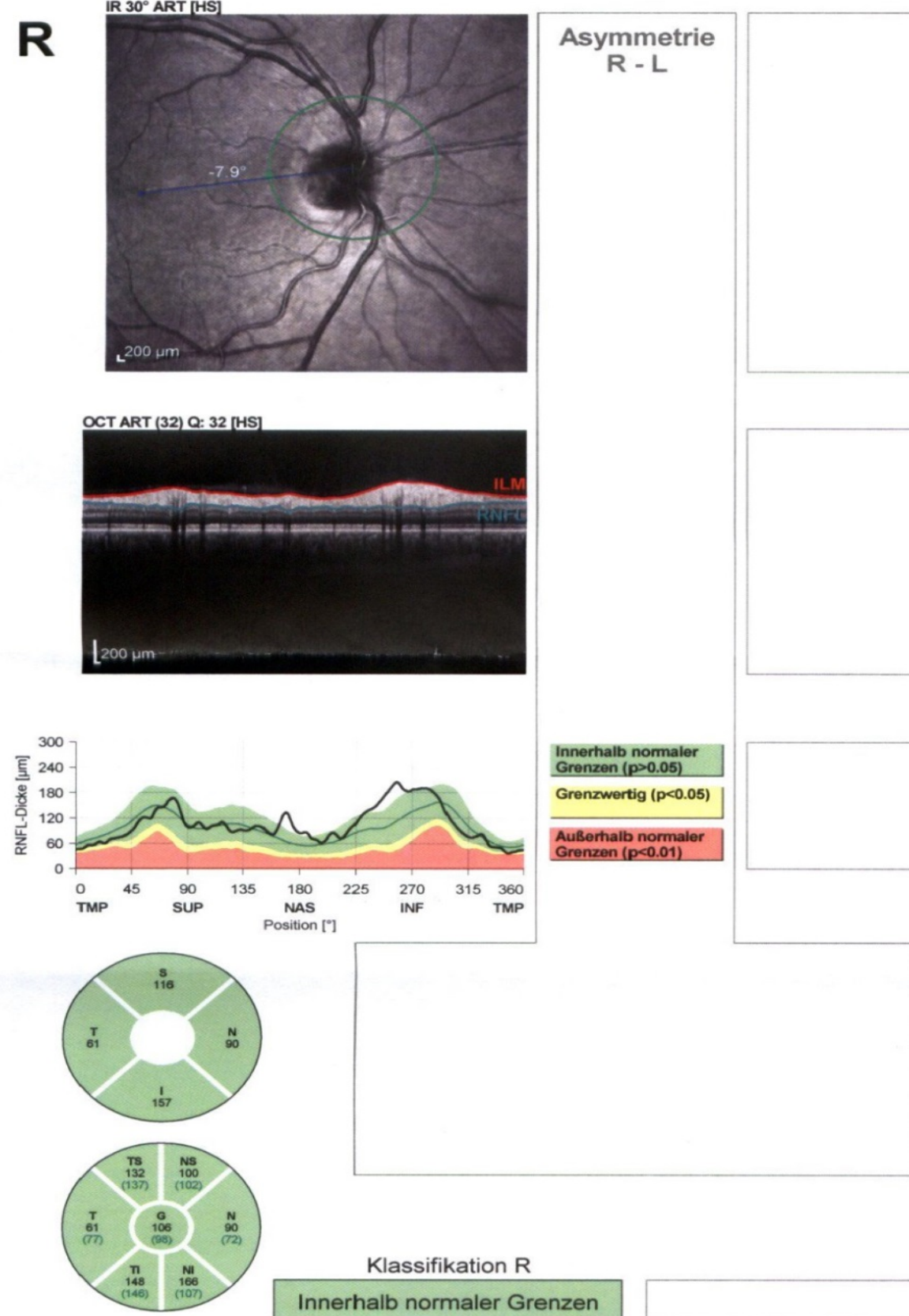

Klassifikation R

Innerhalb normaler Grenzen

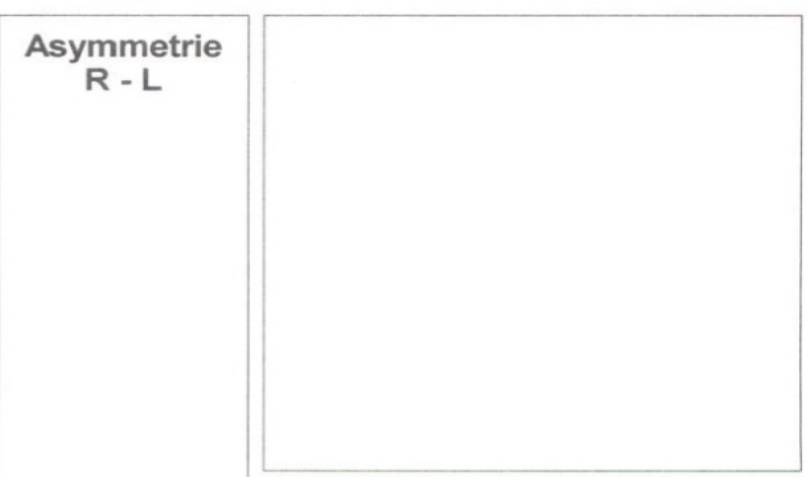

$\mathbf{L}$

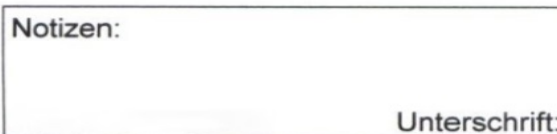

Software Version: 6.3.4

mww. HeidelbergEngineering.com

RNFL-Einzeluntersuchung OU

Figure 6. Retinal Nerve Fiber Layer Analysis by OCT (Right Eye) showing a healthy optic nerve with no optic neuropathy. 
$\mathbf{R}$
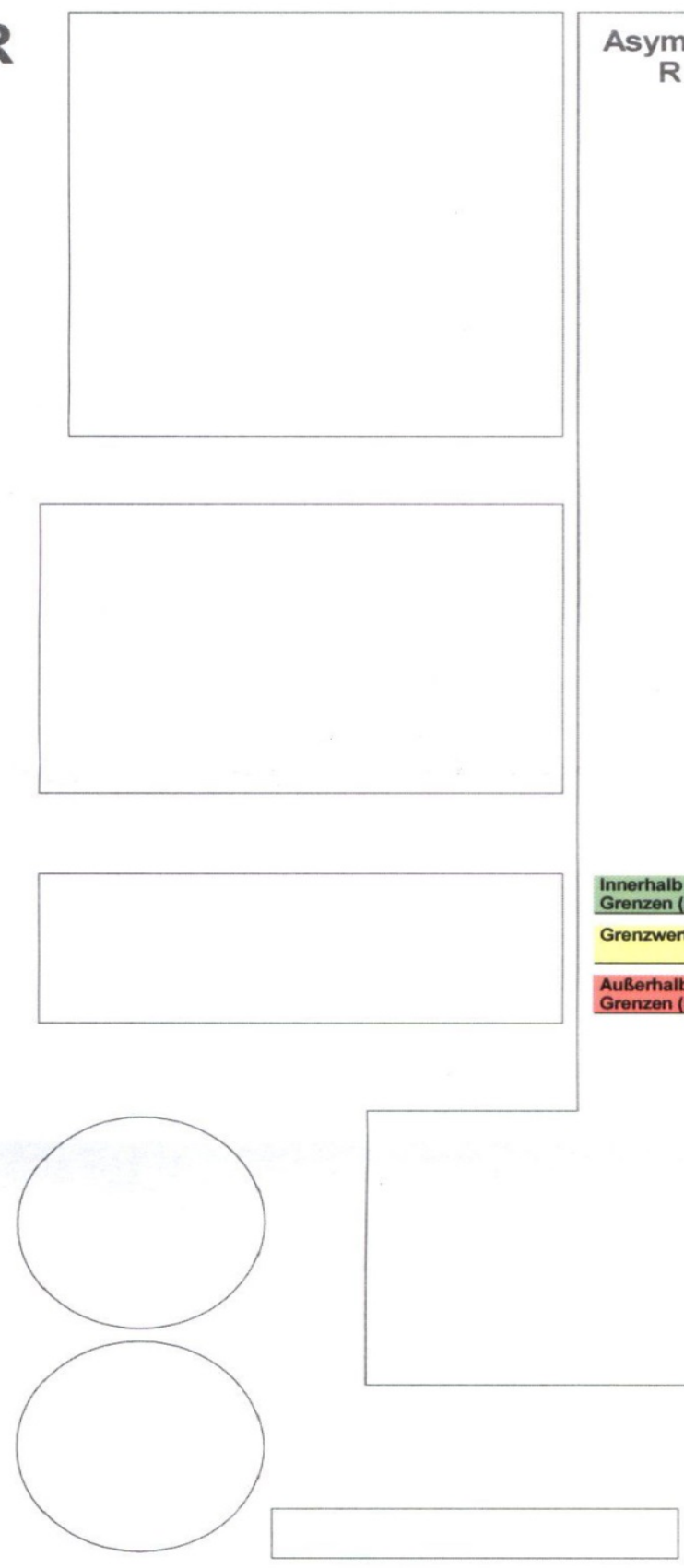
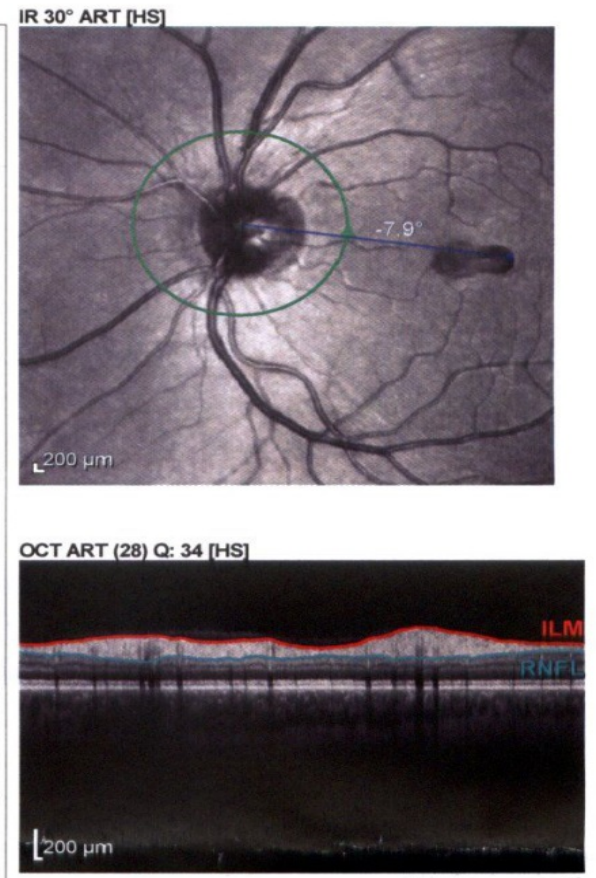

Innerhalb normaler Grenzen ( $p>0.05)$ Grenzwertig $(p<0.05)$ Außerhalb normaler
Grenzen $(p<0.01)$

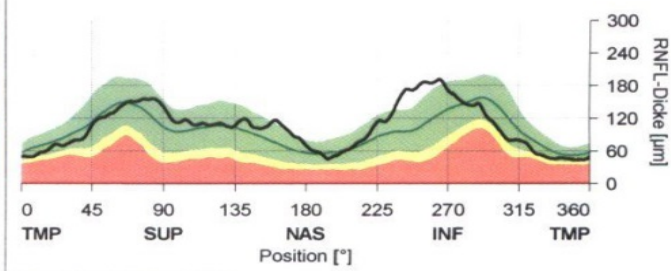

Notizen:

Unterschrift:

Software Version: 6.3.4

www.HeidelbergEngineering.com

RNFL-Einzeluntersuchung OU

Klassifikation L Innerhalb normaler Grenzen
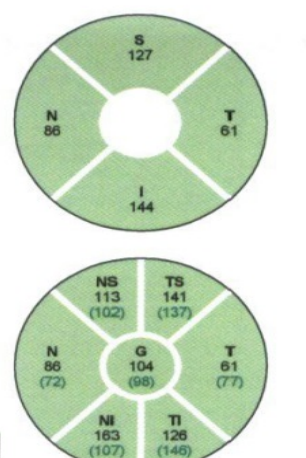
Anemia has been reported as an important risk factor for developing retinopathy in many case series, with a prevalence of 20 $28.3 \%$. The retinopathy was described due to several types of anemia such as iron deficiency anemia, aplastic anemia, sickle cell anemia, beta-thalassemia, pernicious anemia, and drug-induced anemia. We diagnosed megaloblastic anemia as a cause of bilateral subinternal limiting membrane hemorrhage.

The manifestations of anemic retinopathy are nonspecific and may closely simulate hypertensive or diabetic retina. Retinal changes in anemia are cotton wool spots, venous tortuosity, and hemorrhages which may be present at all levels of the retina and choroid. All retinal hemorrhages can occur when $\mathrm{Hb}$ falls below $8 \mathrm{~g} / 100 \mathrm{ml}$ or if the platelet count falls below $50,000 /$ cumm. The combination of severe anemia and thrombocytopenia is likely to produce retinal hemorrhages in a majority of patients.Factors such as anoxia, venous stasis, angiospasm, increased capillary permeability, and thrombocytopenia have been implicated in the pathogenesis of anemic retinopathy [8].

Terson's syndrome is intraocular hemorrhage (IOH) subsequent to subarachnoid hemorrhage ( $\mathrm{SAH})$. Its presence is associated with higher mortality in SAH [9].

\section{References}

1. Sayin N, Kara N, Pekel G (2015) Ocular Complications of Diabetes Mellitus. World J Diabetes 6: 92-108. [Crossref]

2. Wong TY, McIntosh R (2005) Hypertensive retinopathy signs as risk indicators of cardiovascular morbidity and mortality. Br Med Bull 73: 57-70. [Crossref]

3. Waikar S, Srivastava VK (2013) Valsalva retinopathy in a young healthy individual. Med J Armed Forces India 69: 193-195. [Crossref]

4. Nowilaty SR, Al-Shamsi HN, Al-Khars W (2010) Idiopathic Juxtafoveolar Retinal Telangiectasis: A Current Review. Middle East Afr J Ophthalmol 17: 224-241. [Crossref]

5. Penman AD, Serjeant GR (1992) Recent advances in the treatment of proliferative sickle cell retinopathy. Curr Opin Ophthalmol 3: 379-388. [Crossref]

6. Özer MA, Polat N, Özen S, Parlakpınar H, Ekici K, et al. (2016) Effects of molsidomine on retinopathy and oxidative stress induced by radiotheraphy in rat eyes. Curr Eye Res 42: 803-809. [Crossref]

7. Buckley SA, James B (1996) Purtscher's retinopathy. Postgraduate Med J 72: 409-412

8. Kumar VS, Bhogadi P (2016) Bilateral Macular Hemorrhage due to Megaloblastic Anemia: A Rare Case Report. Indian J Ophthalmol 64: 157-159. [Crossref]

9. Hassan A, Lanzino G, Wijdicks EF, Rabinstein AA, Flemming KD (2011) Terson's syndrome. Neurocrit Care 15: 554-558. [Crossref]

Copyright: (C2017 Abdelmseih M. This is an open-access article distributed under the terms of the Creative Commons Attribution License, which permits unrestricted use, distribution, and reproduction in any medium, provided the original author and source are credited. 